\section{Sodium-Glucose Cotransporter 2 (SGLT2) Inhibitors and Stroke}

\section{To the Editor:}

The large-scale EMPA-REG OUTCOME clinical trial ${ }^{1}$ demonstrated for the first time that sodium-glucose cotransporter 2 inhibitors (SGLT2-Is) improved the prognosis for the heart ${ }^{1}$ and kidneys ${ }^{2}$ as well as hypoglycemic drugs, although stroke incidence tended to be increased. ${ }^{1}$ In fact, a meta-analysis showed stroke increased significantly by SGLT2-Is. ${ }^{3}$ Recently, it has become clear that SGLT2-Is have a diuretic action, ${ }^{\mathbf{4}, 5}$ and conventional diuretics are known to effectively suppress stroke ${ }^{6}$ and heart failure. ${ }^{6}$ In the original EMPA-REG, ${ }^{1}$ diuretics were combined with SGLT2-Is in 43.7\%, probably leading to dehydration and/ or hypotension, resulting in cerebral infarction. On the other hand, in an Asian subanalysis ${ }^{7}$ of EMPA-REG, only in $26.7 \%$ of participants were diuretics combined with SGLT2-Is, making the incidence of stroke less. As shown in the Figure, ${ }^{7}$ there was no tendency at all that stroke was increased by SGLT2-Is in the Asian group. These findings indicate careful use of combined diuretics and SGLT2-Is is required because SGLT2-Is themselves have a diuretic action. ${ }^{4,5}$ The heart failure subanalysis findings ${ }^{\mathbf{8}}$ from EMPA-REG ${ }^{1}$ are interesting., ${ }^{\mathbf{5}, \mathbf{8}}$ The prognostic improvements by SGLT2-Is were not significant under treatment including diuretics such as loop diuretics and aldosterone antagonists, suggesting that the prognostic improvement in heart failure by SGLT2-Is was mostly caused by the diuretic action of the SGLT2-Is. ${ }^{5}$ Because SGLT2-Is have a loop diuretic action, ${ }^{\mathbf{4}, 5}$ the co-administration of other diuretics may induce dehydration and/or hypotension as discussed next.

To date, diuretics have conventionally prevented stroke, ${ }^{6}$ as just discussed. Therefore, it is important to understand why SGLT2-Is, which have a loop diuretic action,,5 increased stroke incidence. Combined use of different types of diuretics might result in massive diuresis. If loop diuretics (SGLT2-Is) are administered alone, $\mathrm{Na}$ reabsorption in the distal tubules (site of action of thiazides), located after the loop of Henle, is enhanced in a compensatory manner. ${ }^{5}$ Therefore, actual diuresis is limited. However, SGLT2-Is use in combination with thiazides may cause massive diuresis. Compensatory Na reabsorption by the distal tubules is dependent on aldosterone. ${ }^{\mathbf{5}}$ Therefore, if SGLT2-Is are given with an aldosterone antagonist, not only compensatory reabsorption by distal tubules but also tubular reabsorption in the collecting duct (site of action of aldosterone antagonist) is inhibited, resulting in further massive diuresis. The EMPA-REG data ${ }^{1}$ should be re-analyzed regarding whether such combinations were related to stroke (cerebral infarction) or not. We must pay attention to whether combined use of SGLT2-Is and conventional diuretics causes stroke, probably by volume depletion and hypotension.
Details about the types and doses of diuretics administered were unclear in EMPA-REG. I personally expect that SGLT2-Is without other diuretics may suppress the incidence of stroke. EMPA-REG data about stroke must be further analyzed in detail.

\section{References}

1. Zinman B, Wanner C, Lachin JM, Fitchett D, Bluhmki E, Hantel S, et al. Empagliflozin, cardiovascular outcomes, and mortality in type 2 diabetes. $N$ Engl J Med 2015; 373: 2117-2128.

2. Wanner C, Inzucchi SE, Lachin JM, Fitchett D, von Eynatten M, Mattheus M, et al. Empagliflozin and progression of kidney disease in type 2 diabetes. $N$ Engl J Med 2016; 375: 323-334.

3. Wu JH, Foote C, Blomster J, Toyama T, Perkovic V, Sundstrom $\mathrm{J}$, et al. Effects of sodium-glucose cotransporter-2 inhibitors on cardiovascular events, death, and major safety outcomes in adults with type 2 diabetes: A systematic review and meta-analysis. Lancet Diabetes Endocrinol 2016; 4: 411-419.

4. Kimura G. Importance of inhibiting sodium-glucose cotransporter and its compelling indication in type 2 diabetes: Pathophysiological hypothesis. J Am Soc Hypertens 2016; 10: 271-278.

5. Kimura G. Diuretic action of sodium-glucose cotransporter 2 inhibitors and its importance in the management of heart failure. Circ J 2016; 80: 2277-2281.

6. Psaty BM, Lumley T, Furberg CD, Schellenbaum G, Pahor M, Alderman MH, et al. Health outcomes associated with various antihypertensive therapies used as first-line agents: A network meta-analysis. JAMA 2003; 289: 2534-2544.

7. Kaku K, Lee J, Mattheus M, Kaspers S, George J, Woerle HJ; on behalf of the EMPA-REG OUTCOME ${ }^{\circledR}$ Investigators. Empagliflozin and cardiovascular outcomes in Asian patients with type 2 diabetes and established cardiovascular disease: Results from EMPA-REG OUTCOME ${ }^{\circledR}$. Circ J 2017; 81: 227 234.

8. Fitchett D, Zinman B, Wanner C, Lachin JM, Hantel S, Salsali A, et al. Heart failure outcomes with empagliflozin in patients with type 2 diabetes at high cardiovascular risk: Results of the EMPA-REG OUTCOME $^{\circledR}$ trial. Eur Heart $J$ 2016; 37: $1526-$ 1534.

\section{Genjiro Kimura, MD} Asahi Rosai Hospital, Japan Organization of Occupational Health and Safety, Owariasahi, Japan

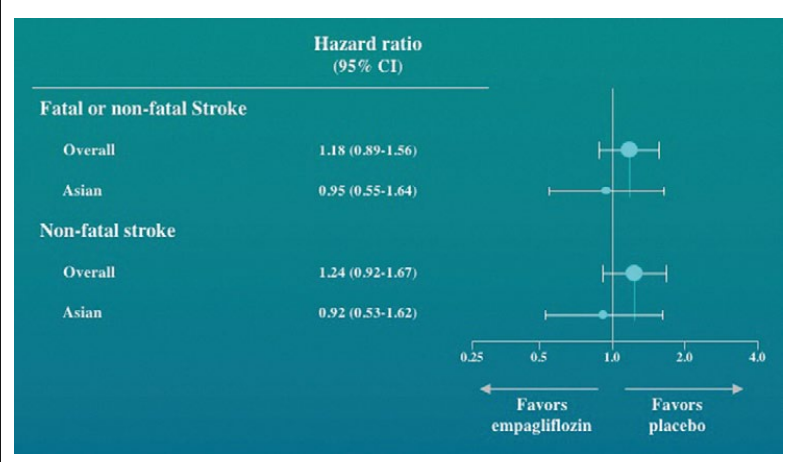

Figure. Stroke incidence (fatal+nonfatal, and fatal) comparison between overall and Asian participants in EMPA-REG trials (modified with permission from Kaku K, et al). ${ }^{7}$ Conventional diuretics were combined in $43.7 \%$ and $26.7 \%$ of overall participants and Asians, respectively.

Received January 13, 2017; accepted January 30, 2017; released online May 10, 2017

Mailing address: Genjiro Kimura, MD, Asahi Rosai Hospital, Japan Organization of Occupational Health and Safety, Hirako-cho North 61, Owariasahi 488-8585, Japan. E-mail: genki@asahih.johas.go.jp

ISSN-1346-9843 All rights are reserved to the Japanese Circulation Society. For permissions, please e-mail: cj@j-circ.or.jp 